\title{
دراسة الاختلافات الور اثية لأنواع نبات الداودي باستخدام مؤشرات AFLP
}

\author{
جَنان قاسم حسين \\ قسم البستنة ، كلية الزراعة ، جامعة بابل ، بابل - العراق.
}

المستخلص

نفذت التجربة في مختبرات التقانات الاحيائية - الهيئة العامة للبحوث العلمية الزراعية - الجمهورية العربية السورية في Amplified Fragment Length Polymorphism صيف 2010. استخدمت تقانة تباينات أطو ال القطع المتضاعفة المعتمدة على تقانة PCR وبخمسة ازو اج من البادئات، لايجاد البصمة الوراثية و النسبة المئوية للبعد الور اثي لخمسة انو اع من نبات الداودي .Chrysanthemum spp (الكروية، العنكبوتية، المفتوحة، الانيمون و البنبون). تضمنت مر احل العمل عزل وتتقية DNA الاجزاء النباتية ثم الكثف عن التباينات بين القطع المتضاعفة لكل نوع بعد ترحيل العينات بجهاز الترحيل الكهربائي. بينت نتائج التحليل الور اثي بمؤشرات AFLP وبعد حساب النسبة المئوية للبعد الوراثي بين الانواع وجود تغايرات ور اثية فيها ، اذ بلغت اعلى نسبة مئوية للبعد الور اثي 45.1\% بين النوعين بنبون والكروية ، و اقلها 17.8\% بين النوعين المفتوحة و الكروية. الكلمات المفتاحية: الداودي ، التتوع الور اثي ، المؤشرات الجزيئية، نقانة تباينات اطو ال القطع المتضاعفة.

و المنشآت اللازمة من اجل المحافظة على الموارد الوراثية خاصة المتعلقة بالزر اعة، وقد نم البدء بعملية حفظ الاصول الور اثية سو اء في الموقع In Situ ضمن الحقول و البراري و المو اقع الاصلية او في بنوك الجينات Gene Banks ومن فورن

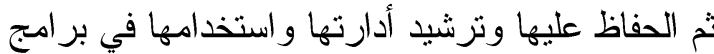
التزبية المختلفة. اوجد التقدم المتسارع في علوم البايولوجيا

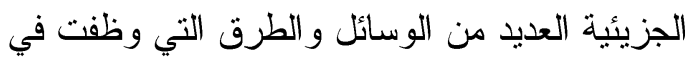
دراسات وتقييم التباينات و العلاقات بين النز اكيب الور اثية،

فهناك العديد من الثقانات الحيوية الحديثة المعتمدة على در استه وتحليل المادة الور اثية، يتم من خلالها استعمال

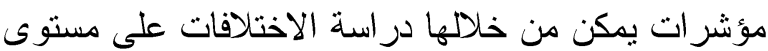
جزيئة DNA، تميزت هذه الطرق بالكفاءة العالية وبالدقة الكبيرة وبنبات النتائج، متغلبة بذلك على محددات الوسائل السابقة المعتمدة على در اسة التباينات على مستوى الصفات الشكلية و الخصائص الفسيولوجية وكذلك الخصائص

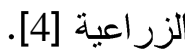

تعد مؤشرات تباينات أطو ال القطع المنضاعفة Amplified Fragment Length Polymorphism (AFLP) تعتمد هذه التقانة على الكثف عن قطع المقيدة بأنزيمات الثقييد و المضاعفة بتفاعل الــ PCR، ثم تحميلها
المقدمة

ينتمي نبات الداودي Chrysanthemum spp. العائلة المركبة compositae، وتعد الصين ومناطق جنوب شرق آسيا المواطن الأصلي لنبات الداودي، ومنها انتشرت

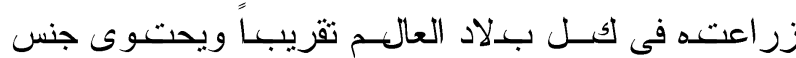
Chrysanthemum على ما يزيد عن 160 نوعاً ويتز ايد

عدد الأصناف التابعة للاودي بإستمر ار نتيجة عمليات التربية و التحسين التي تجرى عليه ، وترجع أهمية نباتات الداودي إلى أن موعد أزهار فى فصل الخريف حيث يقام معرض زهور الخريف اذ نقل أزهار النباتات الأخرى وبالتالى يزداد الإقبال عليه، توجد الاز هار فى نورات متعددة الأشكال والألوان، وتعيش الأزهار المقطوفة لفترة

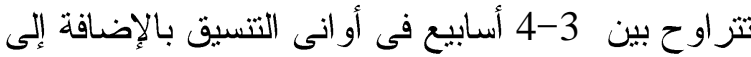

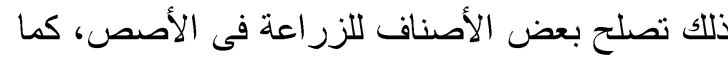
يمكن إنتاج ازهار الكريز انثيمم على مدار السنة إذا أمكن التحكم فى طول الفترة الضوئية [8]. اهتم الباحثون في الاونة الاخيرة بدر اسة التتوع الحيوي

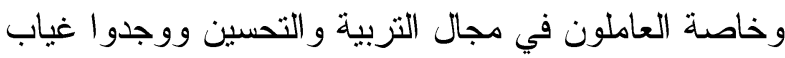

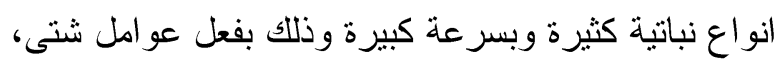
ولمو اجهة هذه التحديات عمل المجتمع الدولي أقطار التهار

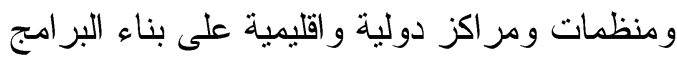


نقية من الفول Vicia faba L. مستنبطة من اصناف عالمية من اسيا واوربا وشمال افريقيا باستخدام تقانة

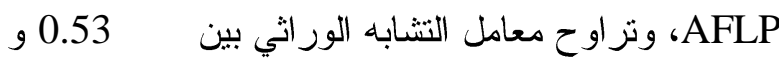

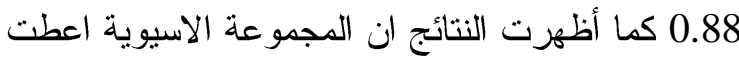
تباينا ور اثيا و اضحا تفوق على مثيله في بقية المجموعات.

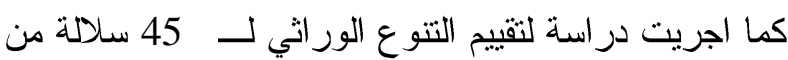
الذرة البيضاء من خلال كل من مؤشرات AFLP و SSR (Simple-sequence repeats) و اوضحت ان اعلى معدل لتقييم التتوع و الاختلافات AFLP كانت قد كثفتها مؤشرات Polymorphism بمعدل قدره 0.65 مقارنة بـ 0.46 لمؤشرات SSR، كما كونشات كان متوسط قيم البعد الوراثي يساوي ( 0.62 و 0.60 و

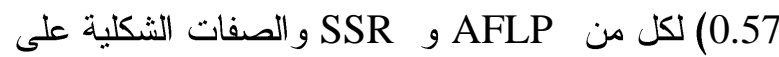

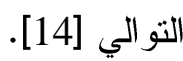
قام Fang و اخرون [13] بدر اسة التتوع الوراثي لــــ 60 سلالة حديثة من اللوبيا . Vigna unguiculata L. خلال 6 ازواج من بادئات AFLP، وكان اجمالي الحزم 382 حزمة وقدر عدد الحزم المتباينة منها بــ 207 حزمة، و انشارو اللى انه بالرغم من تتوع وتباعد اماكن جمع

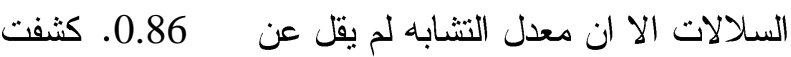
تقانة AFLP عن التغايرات الور اثية التي أحدثها الصعق عند

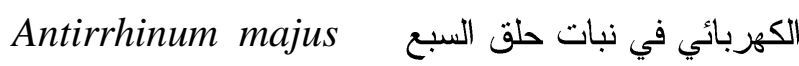
حيث كانت أعلى نسبة للبعد الور اثي 27.5\% عند معات معاملة

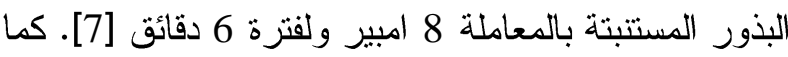
استخدمت مؤشرات AFLP لدراسة وتقويم التتوع الور اثي

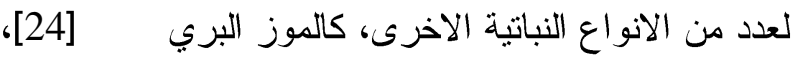

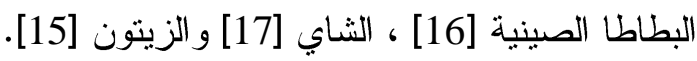

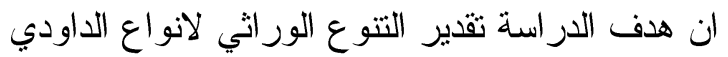

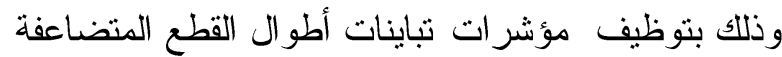
(AFLP) تعطي اكبر عدد ممكن من الحزم المتغايرة، ومن ثم تحديد القرابة الوراثية بين الانواع المستخدمة والهوية الور اثية من

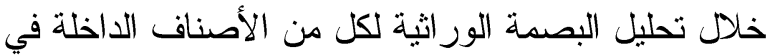
انواع الجنس المدروسة.
Polyacrylamide على هلامة من البولي اكريلامايد

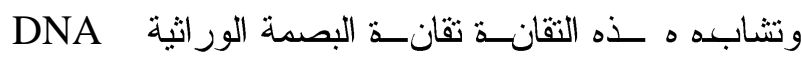
Fingerprinting من التعدادت الثكلية Polymorphism [22].

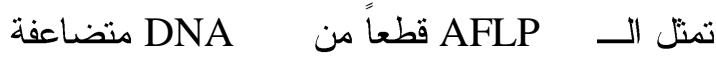
amplified التحديدي restriction digestion لجينوم DNA بادئ وبالاعتماد على أختلاف ترتيب النيوكليوتيدات تعطي هذا

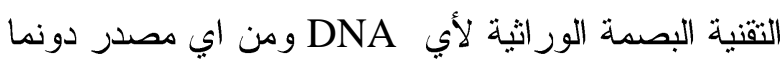
حاجة إلى أية معرفة مسبقة عنه، وقر اءة البيانات بهذه الطريقة تعتمد على مبدأ وجود او عدم وجود مو اقع الجينات إنهات بدلاً من تحديد موقعها أو طولها، تتضمن الطريقة الاستعانة

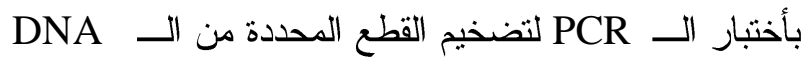
عن طريق هضم الــ DNA بانزيمات التحديد، وربط مولفات adapters على قطع الــ DNA ثم مضاعفة تلك fragment القطع. يمكن تضخيم معدل 85-150 قطعة لكل توليفة بادئات مستخدمة في الاختبار ، وبذلك يتم الحصول على معلومات و اسعة جدا بحسب تعدد البادئات المستخدمة. تمنل كل قطعة تم تشخيصها بهذه الطريقة

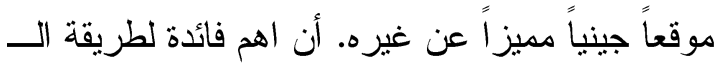
AFLP .[5] Polymorphism تمتاز مؤشرات AFLP بالدقة العالية لقدرتها على اظهار الطرز patterns المميزة لكل فرد فأصبحت الطريقة السائدة و المثلى لبناء البصمة الور اثية لما تمتلكه هذه

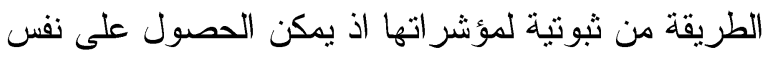

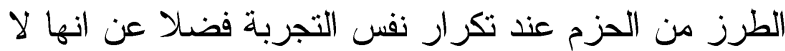
تتطلب معرفة مسبقة بتتابعات DNA المدروس. وتمتاز هذه المؤشرات عن غير ها من مؤشرات DNA بامكانية

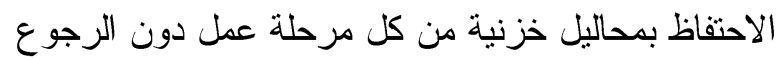
الى تحضيرها مرة اخرى وهذا ما بزيد من امكانية المناورة بنلك المحاليل ولفترات طويلة [10]. استخدمت هذه المؤشرات في عدد كبير من الدراسات و الابحاث، حيث تم من خلالها در اسة وتقويم التتوع الور اثي مدي Genetic Diversity Zeid و اخرون [27] بدر اسة التتوع الوراثي لـــ 79 سلالة 
Sahgi-Maroof و وآخرون [19]، وقدرت كمية الحامض النهووي DNA فـــي العين ـات باستخ ــام جه ــاز (Spectrophotometer Beckman Du-61) الاشعة فوق البنفسجية UV وطول موجي 260 نانوميتر ،

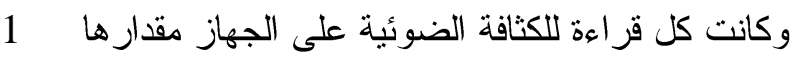
تعادل 50 ميكروغرام من 1/DNA مل من السائل. كما

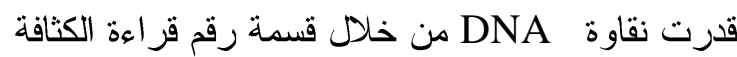
الضوئية عند طول موجي 260 نانومتر على رقم قر اعة

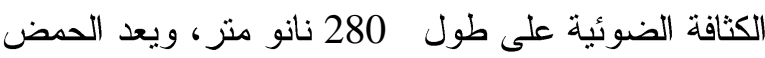

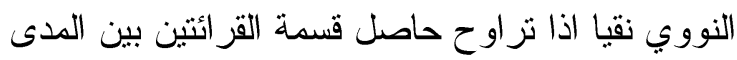

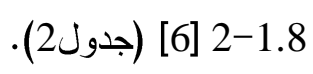

المواد وطر ائق العمل

نفذت التجربة في مختبر التقانات الحياتية في الهيئة العامة للبحوث العلمية الزر اعية - سوريا. استخدمت خمسة

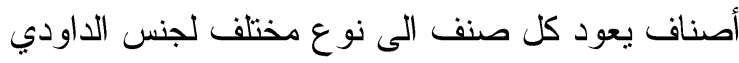
(الكروية، العنكبوتية، المفتوحة، الانيمون و البنبون) و الجدول (1) يوضح بعض الصفات العامة لهذه الأصناف. جمعت الأوراق النظيفة والخالية من الإصابات المرضية بوضية و الحشرية بتاريخ 15-8-2010 ولكل صنف على حدا،

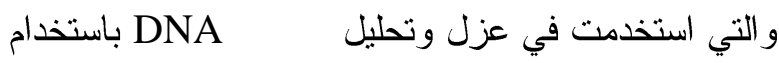

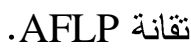

عزلت الاحماض النووية من الاوراق السليمة وفقا لطريقة Weigand و آخرين 25] المعتمدة على طريقة

جدول (1)

بعض الصفات العامة لأصناف الادودي الخمسة.[2] ، [8] ، [11].

\begin{tabular}{|c|c|c|c|c|c|c|}
\hline صفات عامة & الزهزة & الاز هار & الز هرة & الافرع علد & التبات ارتمم & النوع \\
\hline فوق فتاز الاز هار بشكلها الكروي المنتظم ،بتلاتها & قطمر & قليل & كبير & الافرع & $100-70$ & كروية \\
\hline 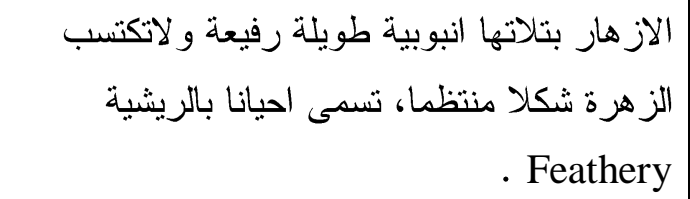 & قطمر & قليل & كبير & الاقرع & $80-60$ & $\begin{array}{l}\text { عنكبوتية } \\
\text { Spidery }\end{array}$ \\
\hline فوق بعض فلا تغطي قرص النورة النكل ولكن تتهدل البتلات بعضها & قطمر & متوسط & كبير & متوسط & $90-60$ & $\begin{array}{c}\text { مفتوحة } \\
\text { Reflexed }\end{array}$ \\
\hline الاز هار لاتحتوي على اكثر من صفين من البتلات & قاطية & كثير & صغير & 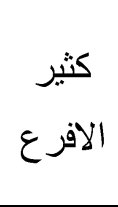 & $60-40$ & $\begin{array}{c}\text { أنيمون } \\
\text { Anemone }\end{array}$ \\
\hline 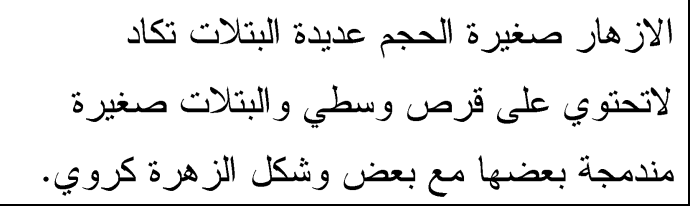 & قطمر & 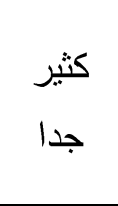 & صغير & 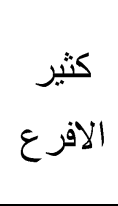 & $50-30$ & $\begin{array}{c}\text { بمبون } \\
\text { Pompon }\end{array}$ \\
\hline
\end{tabular}

البادئات المختبرة (جدول 3) ونم اعتماد نتائجها في تحليل

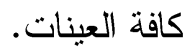

أجريت تفاعلات ( PCR-AFLP) وفقا لــ لـ Vos واخرون [23]. مررت نواتج التفاعل عبر هلامة من البولي
تم استعمال 10 ازو اج من بادئات AFLP للمضاعفة الانتخابية وذلك بهدف اختبار افضل البادئات في اعطاء نتائج و اضحة ودقيقة وقادرة على كثف نسبة مناسبة من التباينات الور اثية ، و وعليه تم اختيار خمسة ازو اج من 
جنَان قاسم حسين

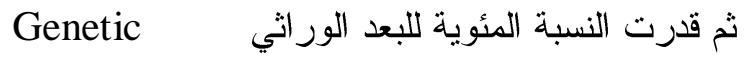

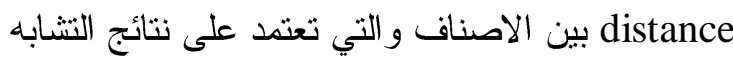
الوراثي وفقا للمعادلة الآتية:

Genetic distance $=1-(2 \mathrm{nxy} / \mathrm{nx}+\mathrm{nyx}) 100$

$$
\text { حيث ان : }
$$

و x : تمنل عدد الحزم المشتركة بين النموذجين : nxy

$$
\begin{aligned}
& \text { y و التي تمثل صنفين من الاصناف. }
\end{aligned}
$$

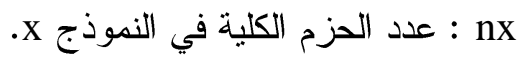

$$
\begin{aligned}
& \text { y عد الحزم الكلية في النموذج : : عy }
\end{aligned}
$$

اكريلمايد تركيزها 6 \% فهاز الترحيل الكهربائي العامودي لمدة ساعة ونصف وبوجود المحلول القياسي 1X TBE

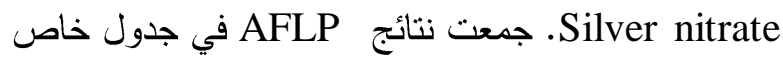
أعتمادا على وجود او غياب قطع DNA للعينات المختلفة، حيث رمز لوجود قطعة دNA المتضاعفة بالرقم 1 ولعدم

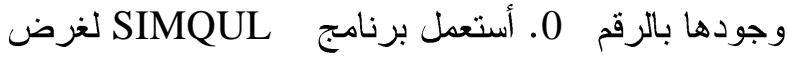
ايجاد العلاقة الور اثية بين الاصناف الداخلة في هذه الدراسة، يعتمد هذا البرنامج على معادلة قيم التشابه لئه Similarity Similarity $=2 \mathrm{nxy} / \mathrm{nx}+\mathrm{ny}$

\begin{tabular}{|c|c|c|c|}
\hline $260 / 280$ & A280 & A260 & عينات DNA الاصناف \\
\hline 2.0461 & 0.2361 & 0.4747 & Sروية Incurved \\
\hline 2.0219 & 0.1242 & 0.2420 & Sنكبوتية Spidery \\
\hline 2.0165 & 0.1607 & 0.3108 & مفتوحة Reflexed \\
\hline 2.0566 & 0.1711 & 0.3412 & أنيمون Anemone \\
\hline 2.0152 & 0.1880 & 0.3639 & بمبون Pompon \\
\hline
\end{tabular}

جدول (2)

جدول (3)

البادئات وانزيمات التحديد وتسلسلها النيوكليوتيدي المستخدمة بتقانة AFLPA.

\begin{tabular}{|c||c||}
\hline \multicolumn{1}{|c||}{ Primer } & 3 Sequence 5 \\
\hline M39-E58 & $\begin{array}{c}\text { GATGAGTCCTGAGTAAAGA - } \\
\text { GACTGCGTACCAATTCCGT }\end{array}$ \\
\hline M39-E47 & $\begin{array}{c}\text { GATGAGTCCTGAGTAAAGA - } \\
\text { GACTGCGTACCAATTCCAA }\end{array}$ \\
\hline M39-E44 & $\begin{array}{c}\text { GATGAGTCCTGAGTAAAGA - } \\
\text { GACTGCGTACCAATTCATC }\end{array}$ \\
\hline M64-E33 & GATGAGTCCTGAGTAAGAC - \\
MACTGCGTACCAATTCAAG
\end{tabular}


لتسلسلات تلك البو ادىء في جينوم نباتات الداودي

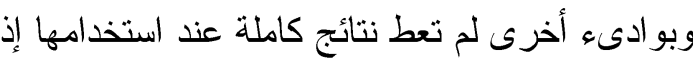
يلاحظ فقدان الحزم في بعض العينات المدروسة. بذلك فقد

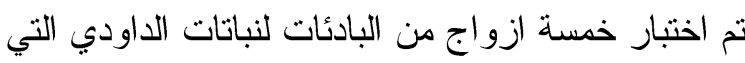
أظهرت تباينات و اضحة بين الانواع المختارة (شكل 1).

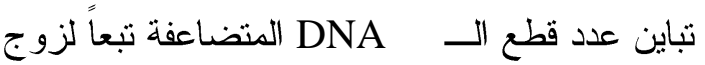

البادئات المستخدم (جدول 4) 4)، حيث تراين عح عدد الحزم M64- المتضاعفة من 33حزمة باستخدام زوج البادئات

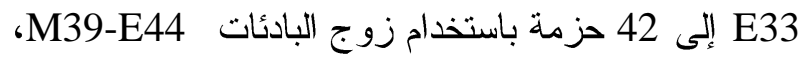

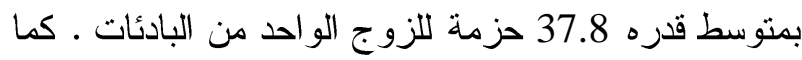

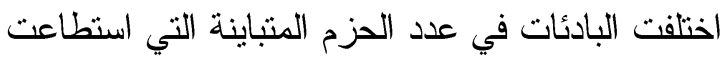
التعرف عليها، حيث تراوحت هذه النسبة ما بين 22 حزمة مع زوج البادئات MNA زوج البادئات M39-E44 وبمتوسط يساوي 26 حزمة متباينة من الــ DNA لكل زوج من البادئات و هذا يقابل

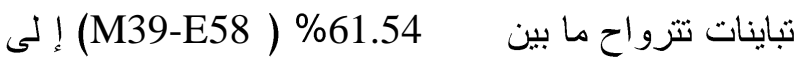
\%73.81 (M39-E44). كان اجمالي عدد حزم الـ الـ

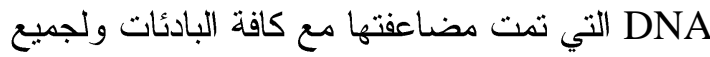

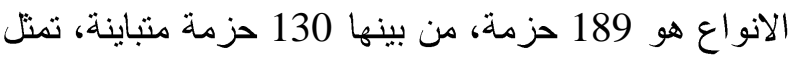
نسبة 68.69\% من كامل الحزم (جدول4).

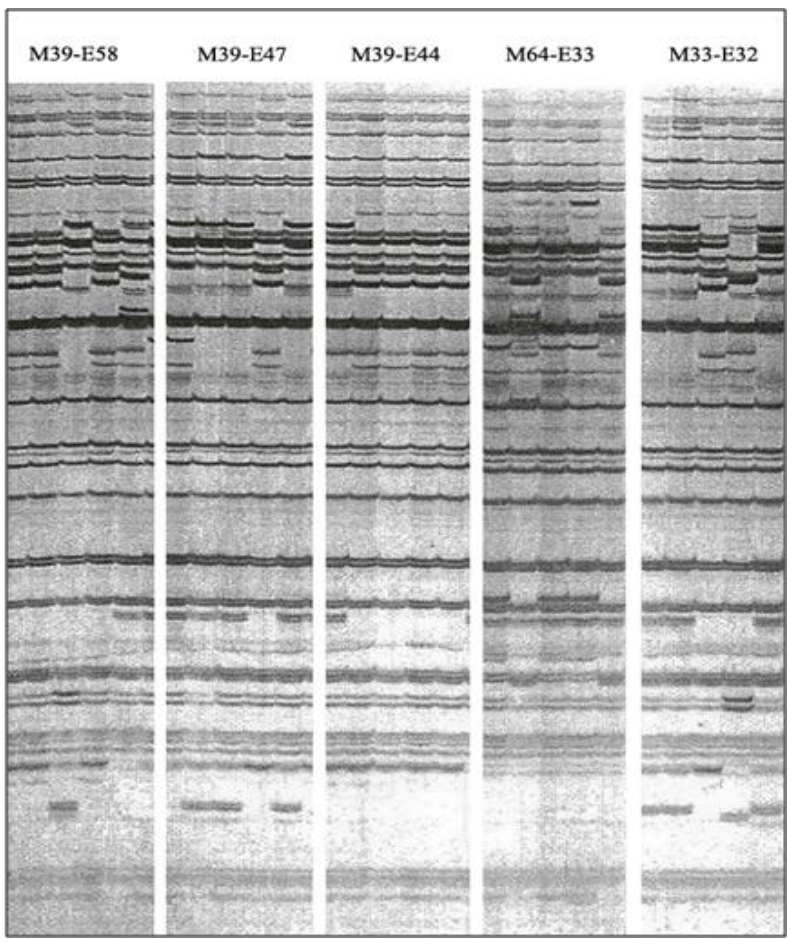

شكل(1). نتائج تحليل DNA الاصناف الخمسة لنبات الا ودي بتقانة AFLP مع توليفة البادئات الخمسة و المرحلة كهربائياً على هلام البولي أكريلاميد بتركيزئهة
النتائج والمناقشة

اعتمدت طريقة تحـليل نتائج در اسة العـلاقة الور اثية على وجود أو غياب الحزم الناتجة من تضاعف قطع معينة من جينوم النباتات المستخدمة وعلى الأوزان الجزيئية لتلك فئك الحزم التي تعتمد على العدد و المو اقع المكملة لتسلسلات البادئات على شريط لمئ DNA القالب ، اهملت الحزم الخفيفة جدا، ويتفق هذا مع [12] و [20].

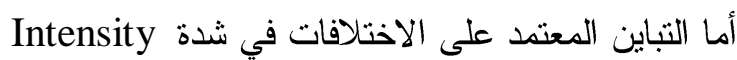

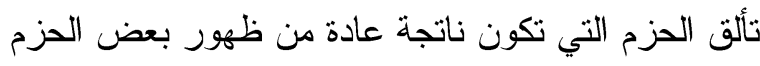

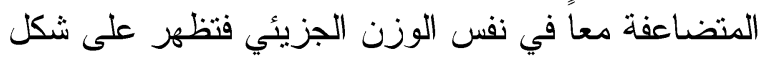
حزمة سميكة واحدة (هي بالحقيقة أكثر من حزمة قد تكون ناتجة من حالة (Comigrating bands homozygotsity الاليل الآخر ، وبما أنها بنفس الوزن الجزيئي لذلك تتجمع القطع المنضاعفة في تللك المو اقع معا، و أحيانا زيادة تركيز

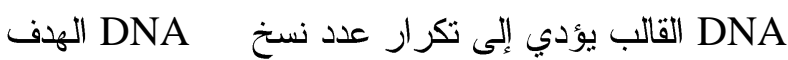
مما يؤدي الى تضاعف نفس الموقع أكثر من مرة وبما ان التزكيز الدقيق للـ DNA يكون من الصعوبة تحديده لتاثره

بعدة عو امل لذلك لا يمكن استخدام الاختلاف في سمك هن

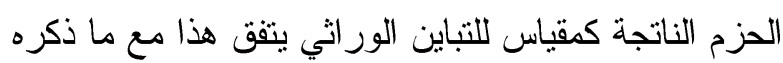

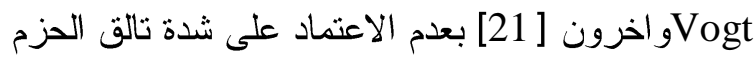

كمقياس للتباين لصعوبة ضبط التركيز الدقيق DNA.

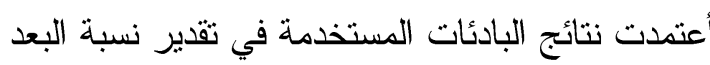
الور اثي Genetic distance بين كل صنفين من الاصناف المنتخبة و الموصوفة من قبل LiوNei [ 18 و التي تستند على وجود الحزم المشتركة بين زوج من تلك النباتات .

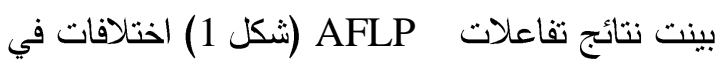
عدد الحزم المتضاعفة وأوز انها الجزيئية باختلاف البادئ المستخدم والناتجة من الاختلاف في عدد المو اقع المكملة لذلك البادئ في جينوم كل نبات من النباتات المدروسة. يتفق هذا مع جميع النتائج المنشورة في هذا المجال منها

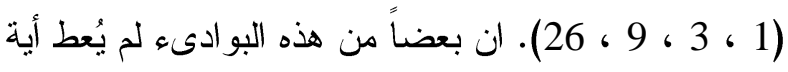
نتيجة بالرغم من إعادتها أكثر من مرة ويتفق ذلك مع دم نتائج

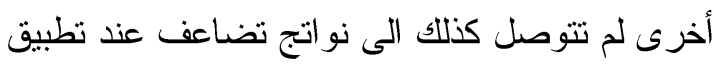

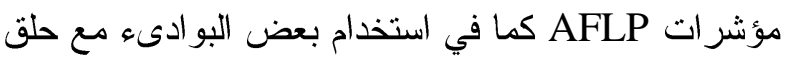
السبع [7] و الشعير [ [4] وذلك بسبب غياب المو اقع المكملة 


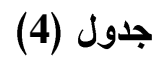

العدد الكلي لحزم DNA وعدد الحزم المتباينة التي كثفتها بادئات AFLP في جميع اصناف الاودي المدروسة.

\begin{tabular}{|c|c|c|c|}
\hline التباين\% & عدد الحزم DNA المتباينة & العدد الكلي لحزم DNA & أزواج البادئات المدروسة \\
\hline 61.54 & 24 & 39 & M39-E58 \\
\hline 62.86 & 22 & 35 & M39-E47 \\
\hline 73.81 & 31 & 42 & M39-E44 \\
\hline 72.73 & 24 & 33 & M64-E33 \\
\hline 72.5 & 29 & 40 & M33-E32 \\
\hline- & 130 & 189 & المجموع \\
\hline 68.69 & 26 & 37.8 & المتوسط \\
\hline
\end{tabular}

و الكروية على التو الي (جدول5) مع كونهم ينتمون الى نفس المجموعة (مجموعة الازهار كبيرة الحجم) ويعود سبب هذا الاختلاف الور اتي الى عمليات التربية و التحسين من تهجين وتطفير التي اجريت على النوع العنكبوتية الازهار لتغيير

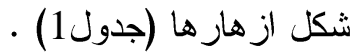

اما اقل نسبة مئوية للبعد الوراثي اعطاها النوع كروي

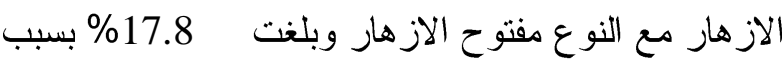
التشابه العالي في الصفات المظهرية لهما وكونهما يعودان الى مجموعة الازهار كبيرة الحجم (جدول1). نستتتج مما تقدم ان مؤشرات

التغايرات الور اثية بين انو اع الداودي المدروسة من خلال تحليل نتائج البصمة الور اثية المعتمدة على ازواج البادئات الخمسة التي بينت هذه الاختلافات دون الحاجة الى اختبار

العديد من البادئات. كما نلاحظ ان النسبة المئوية العالية للبعد الور اثي تكون بين الانواع التي تتنمي الى مجاميع مختلفة (مجموعة الازهار الكبيرة الصغيرة) بينما تكون النسبة المئوية للبعد الور اثي قليلة بين

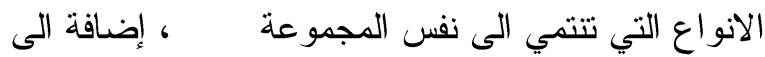

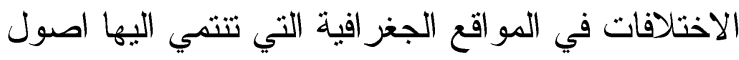
الانواع الداخلة في الدر اسة.
بعد إدخال البيانات الناتجة من استخدام البادئات في البرنامج المعد خصيصا لهذا الغرض على الحاسب الآلي تم إيجاد البعد الوراثي Genetic distance بين الاصناف المختارة وكما موضح في الجدول [5]. يتبين من نتائج جدول [5] عدم وجود تشابه تام بين أبي من الانواع المدروسة وبالتالي امكن تمييز كافة المدخلات التي تم در استها، حيث اعطى نبات الداودي نوع بنبون نسبة مئوية للبعد الور اثي مرتفعة مع باقي الانواع وكانت اعلاها 45.1\% مع النوع الكروي الازهار ثم تلتها

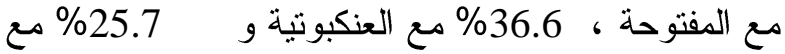
الانيمون، قد يعود سبب البعد الور اثي العالي بين البنبون و الانواع الكروية ، المفتوحة و العنكبونية لكونه لاينتمي الى لى لوني نفس مجموعة هذه الانو اع التي تتميز بحجم ازهار ها الكبير و النبات مرتفع وقلة عدد ازهاره على العكس من نبات البنبون قليل الارتفاع وذو ازهار كثيرة العدد وصغيرة الحجم (جدول 1)، بينما كانت النسبة المئوية للبعد الوراثي تقل مع النوع انيمون لكونهما ينتميان الى نفس المجموعة (مجموعة الازهار صغيرة الحجم). اختلف النوع انيمون مع باقي انواع الداودي وبنسب

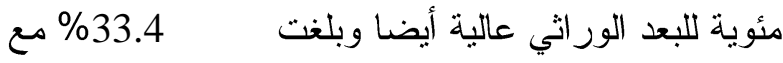
الكروية، 31.9\% مع المفتوحة و 27.2\% مع العنكبوتية

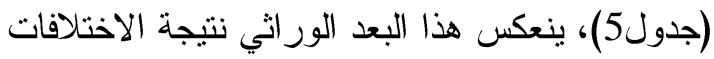

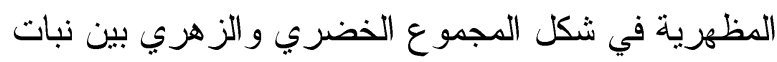
الانيمون و الانواع السابقة الذكر وكما موضح في جدول [1]. اعطى نوع الداودي ذو الازهار العنكبوتية نسب مئوية

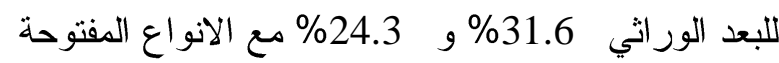


(5) جدول

البعد الور اثي (\%) بين انواع الداودي اعتمادا على البيانات الناتجة من استخدام ازواج البادئات الخمسة في مؤشرات .AFLP

\begin{tabular}{|c|c|c|c|c|c|}
\hline $\begin{array}{c}\text { بمبون } \\
\text { Pompon }\end{array}$ & $\begin{array}{c}\text { أنيمون } \\
\text { Anemone }\end{array}$ & $\begin{array}{c}\text { مفتوحة } \\
\text { Reflexed }\end{array}$ & $\begin{array}{c}\text { عidery } \\
\text { Spideryة }\end{array}$ & $\begin{array}{c}\text { كروية } \\
\text { Incurved }\end{array}$ & الانواع \\
\hline & & & & 0.0 & كروية Incurved \\
\hline & & & 0.0 & 24.3 & Sidery عبوتية \\
\hline & & 0.0 & 31.6 & 17.8 & مفتوحة Reflexed \\
\hline & 0.0 & 31.9 & 27.2 & 33.4 & أنيمون Anemone \\
\hline 0.0 & 25.7 & 42.9 & 36.6 & 45.1 & Pompon بمبون \\
\hline
\end{tabular}

[7] حسين، جَنان قاسم، كاظم ديلي و سامي كريم محمد امين. تأثير الصعق الكهربائي في DNA نبات حلق السبع. مجلة العلوم الزر اعية العراقية. 39(5) : 38.2008 .51

[8] خضر ، محمود. نباتات الزينة. كلية الزر اعة- جامعة

حلب- وزارة التعليم العالي- الجمهورية العربية السورية.ع ص 236 3. 2001. [9] خير اله، حسام سعد الدين محمد. الاكثار الدقيق لصنفين من نخيل التمر بأستخدام النورة الزهرية ودر اسة الثبات الور اثي بأستخدام مؤشرات تباين اطوال قطع الــ DNA المتضاعفة ( AFLP). أطروحة دكتور اه. قسم البستتة- كلية الزر اعة. جامعة بغداد.ع

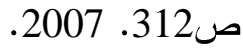

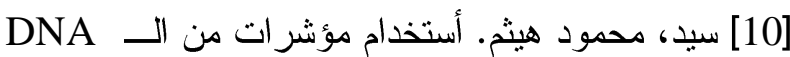

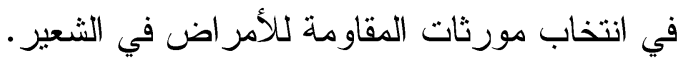
رسالة ماجستير . قسم المحاصيل الحقلية- كلية الزراعة.

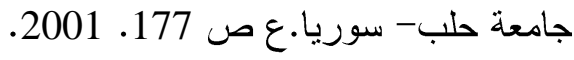
[11] شريتح، محمد علي و مها عبد اللطيف. نباتات الزينة و هندسة الحدائق. وزارة التعليم العالي - جامعة تنرين

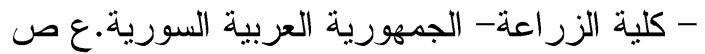
.2004.362

[12] Barone, A., A. Sebastiano and D. Carputo. Chromosome pairing in Solanum commersonii, S. tuberosum sexual hybrids detected by commersonii-specific RAPDs and cytological analysis. Genome 42: 218 -224. 1999.

[13]Fang, J., C. Chao, P. Roberts and J. Ehlers. Genetic diversity of cowpea in four West
(المصادر

[1] أثنتر، سها. تحديد وتقدير النتوع الحيوي في الثعير بأستخدام معلمات الحامض النووي DNA. رسالة ماجستير ـ قسم المحاصيل الحقلية ـكلية الزر اعة. جامعة حلب - سوريا .ع ص 126. 1999.

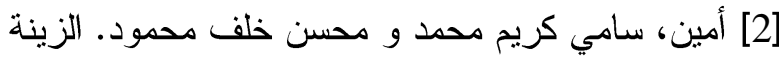

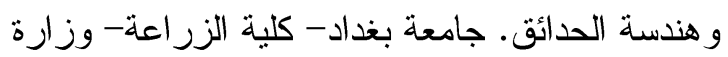

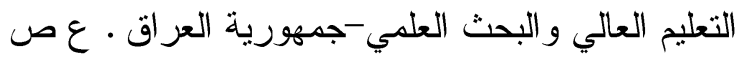
.1989.424

[3] الحسني، خلود ابر اهيم حسن. استخدام المؤشرات الجزيئية المعتمدة على التفاعل التضاعفي لسلسلة الدنا

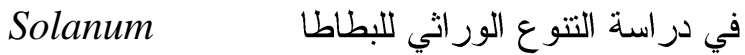
tuberosum L. علوم الحياة. جامعة بغداد.ع ص 200. 2002. [4] الخو لاني، محمد العزي. دراسة التباينات الور اثية لاصناف الشعير في الجمهورية اليمنية بأستخدام المؤشرات الجزيئية للــــA DNA. اطروحة دكتور اه. قسم المحاصيل الحقلية. كلية الزر اعة. جامعة تشرين. الجمهورية العربية السورية. ع ص 132. 2008. [5] الساهوكي، مدحت مجيد. تربية النبات بمساعدة المعلمات الجزيئية. مجلة العلوم الزر اعية العر اقية. .2006.72-67: (4)37 [6] سين، جَنان قاسم. تأثير الصعق الكهربائي في تغايرات النمو الخضري والزهري و DNA بعض فئن نباتات الزينة ـ اطروحة دكتور اة. قسم البستتة. كلية الزر اعة. جامعة بغداد. جمهورية العراق.ع ص الرسان 141. .2007 
Frijters, J. Pot, J. peleman, M. Kuiper and M. Zabeau. AFLP: a new technique for DNA fingerprinting. Nucleic Acids Research 23 (21): 4407 - 4414. 1995.

[24]Wang, X., T. Chiag , N. Roux, G. Hao and X. Ge. Genetic diversity of wild banana in China as revealed by AFLP markers. Genetic Resources and Crop Evolution. 54:1125-1132. 2007.

[25]Weigand, F., M. Baum, and S. Udupa . DNA molecular marker techniques. Technical manual. No. 20 International Research for Agricultural reaearch in the Dry Areas, Aleppo, Syria. 1993.

[26]Williams, J., A. R. Kubelik, K., J. Livak, J. A Rafalaki and S. V. Tingey. DNA polymorphisms amplified by arbitrary primers are useful as genetic markers. Nucleic Acids Research 18 (22): 6531 6535. 1990.

[27]Zeid, M., C. Schon and W. Link. Genetic diversity in recent elit Faba bean lines using AFLP markers. Theoretical and Applied Genetic. 107(7 : 1304-1314. 2003.

\section{Abstract}

The study was carried out at biotechnology laboratories- GCSAR- Syria in summer season 2010. The Amplified Fragment Length Polymorphism (AFLP )based on Polymerase Chain Reaction (PCR) with five primers were applied, was used to estimate fingerprinting and Genetic Distance for five cultivars of Chrysanthemum spp. (Incurved, Spidery, Reflexed, Anemone and Pompon). Phases of work included, the isolation and purification of DNA plant parts and DNA polymorphisms were scored within amplified fragments by electrophoresis. The genetic analyses by using AFLP and Genetic Distance for Chrysanthemum cultivars genetic variability were determinately. High Genetic Distance Chrysanthemum cultivars $(45.1 \%)$ in AFLP markers was registered between the two cultivars (Pompon $\mathrm{X}$ Incurved) and were found the lowest Genetic Distance (17.8\%) between (Reflexed X Incurved) .

Keywords: Chrysanthemum spp., Genetig diversity, Molecular markers, AFLP.
African and USA breeding programs as determined by AFLP analysis. Genetic Resources and Crop Evolution. 54: 11971209. 2007.

[14]Geleta, N., M. Labuschagne and C. Viljoen. Genetic diversity analysis in sorghum germplasm as estimated by AFLP, SSR and morpho-agronomical markers. Biodiversity and Conservation. 15(10); 3251-3265. 2006

[15]Gratikamoun, N., F. Mahmoud and A. Seer. Genetic diversity of Tunisian olive tree cultivars assessed by AFLP markers. Genetic Resources and Crop Evolution. 53(2: 265-275. 2006.

[16]Hong, H., C. Yili and J. Liping. Genetic diversity analysis of some Chinese cultivated potato varieties by AFLP. Acta Horticulturae Sinica. 33(6): 1349-1352. 2006.

[17]Jianan, H., L. Jiaxian, H. Junwu and L. Zhihua.2006. Genetic diversity of tea cultivars revealed by AFLP analysis. Acta Horticulturae Sinica. 33(2): 317-322.

[18]Nei, M. and W.H. Li . Mathematical model for studying genetic variation in terms of restriction endonucleases. Proc. Nat. Acad. Sci. USA. 74:5269 - 5273. 1979.

[19]Sahgi-maroof, M.A., K.M. Soliman, R.A. Jorgens and R. W. Allard. Ribosomal DNA spacer lenth polymorphisms in barley. Proc. Natl. Acad.Sci.USA.81: 8014 $-8018.1984$.

[20]Swoboda, I. and P. L. Bhalla . RAPD analysis of genetic variation in the Australian sun flower Scaevola. Genome, 40: 600 - 606. 1997.

[21]Vogt, T., M. Francoise, K. Frank, J. Welsh and M. Clelland . Fingerprinting of DNA and RNA using arbitrarily primed PCR. IN: G. Anolles and P. M. Gresshof (eds.). DNA Markers, Protocols, Application and Overview. New York. p.55-74. 1997.

[22]Von, B., R. N. Jacobsen, C. Baden, R.B. Jorgensen and Linde- Laursen. An Ecogeographical Studies on Crop Genepools 7. International Plant Genetic Resources Institute. Rome. 1995.

[23]Vos, P., R. Hogers, M. Bleeker, M. Reijans, T.V.D. Lee, M. Hornes, A. 